\title{
Defect of neutrophil mobility with dominant inheritance in a family with Waardenberg's syndrome
}

\author{
A R HAYWARD, R MOWLA, AND BETTY HARVEY \\ Department of Immunology, Institute of Child Health, London, and Northgate Hospital, Great Yarmouth, \\ Norfolk
}

SUMMARY A family with Waardenberg's syndrome and recurrent infections is described. Immunological studies showed defective neutrophil mobility in vitro (which could account for the susceptibility of such patients to infection), and the presence of high serum IgM levels.

Defects of neutrophil mobility are being recognised in an increasing number of patients with recurrent pyogenic infections. ${ }^{1}$ In many patients it is difficult to determine whether the neutrophil defect is primary or secondary. As with other types of immunodeficiency, family studies, in which inheritance can be established, afford a good opportunity to define the disorder. ${ }^{2}$ We describe a family with both a dominantly-inherited defect of neutrophil mobility and Waardenberg's syndrome (lateral displacement of the epicanthic folds, deafness, and pigmentary defects of hair and iris).

\section{Case reports}

Case 1. (Figure, II 5.) This trawler master had died in his fifties of a presumed coronary thrombosis. He had been partially deaf since childhood; he had had a white forelock and had greyed prematurely. The only record of infection is that of a chronic otitis media in his forties.

Case 2. (Figure, II 6.) The third wife of Case 1 is alive at age 71 . She became deaf at about 5 years and at 49 this was diagnosed as congenital nerve deafness. No pigmentary disturbances are recorded in her family.

Case 3. (Figure, III 2.) The second son of Case 1 was fostered because his mother had died 4 days after his birth. He had a white forelock and had been considered to be a weak child because of frequent chest infections. He had died at age 14 of pneumonia complicated by meningitis.

Case 4. (Figure, III 3.) This is the first son of Cases 1 and 2. He had had a white forelock and was investigated for malabsorption syndrome at 2 years. At 11 years his spleen was enlarged to the umbilicus and he had abnormal skin pigmentation and bronchiectasis. An enlarged cervical lymph node biopsied at 15 years showed reactive hyperplasia. He died at age 27 after recurrent chest infections.

Case 5. (Figure, III 4.) The second son of Cases 1 and 2 is alive and healthy at age 44 .

Case 6. (Figure, III 5.) The only daughter of Cases 1 and 2 is aged 32. A white forelock was present in childhood but has become less apparent now that her hair is lighter. She has had frequent chest infections since infancy and was found to be deaf at 11 months after an attack of measles. At age 7 she was investigated because of splenomegaly: fair skin, perceptive deafness, and bronchiectasis were found. Biopsy of an enlarged inguinal lymph node showed reactive changes only.

Case 7. (Figure, III 6.) The husband of Case 6 is healthy.

Case 8. (Figure, IV 1.) The first daughter of Case 6 is aged 7. She was born at term by normal delivery and has a congentially dislocated left hip. Recurrent upper and lower respiratory tract infections started

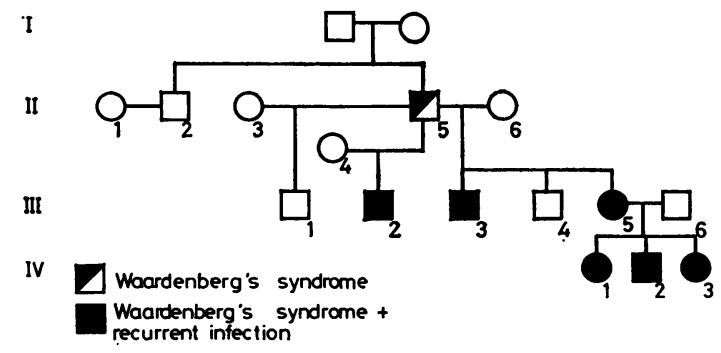

Figure The family tree. 
in infancy and at age 3 she was below the 3rd centile for height and weight. She has had several severe episodes of lobar pneumonia and has been on antibiotics since age 4 . Splenomegaly has been present since age $4 \frac{1}{2}$. Audiometry at age 7 showed partial perceptive deafness.

Case 9. (Figure, IV 2.) The first son of Case 6 is aged 4. He was born at term by normal delivery and was immunised with BCG as a neonate. Recurrent cough started in infancy and he first had pneumonia at age 12 months. Subsequently he has had severe episodes of diarrhoea and bilateral otitis media. At age 2 he had splenomegaly, cervical lymphadenopathy, and café-au-lait spots over one shoulder. Audiometry showed partial perceptive losses bilaterally.

Case 10. (Figure, IV 3.) The second daughter of Case 6 is aged 3. After a term normal delivery she was immunised with BCG as a neonate. Recurrent upper and lower respiratory tract infections started in infancy. Splenomegaly was found at age 1 , and at 2 years she had a watery right eye with ptosis. Examination showed right microphthalmia, iris atrophy, posterior synechiae, and retinal detachment. No response was detected by audiometry.

\section{Investigations}

Cases 4 and 6 were investigated because of splenomegaly and frequent infections; their brother (Case 5) was investigated too although he was symptomless. Their blood counts and urine samples were normal, and lymph node biopsies and marrow films showed only reactive hyperplasia and no evidence of storage disease. Blood count, and levels of sweat sodium, and $\alpha$-l-antitrypsin were normal in Cases 8, 9 , and 10, although blood neutrophil counts did not rise above $5.4 \times 10^{9} / 1$ even during severe infections. Tests of specific immunity (Table 1) and complement (Table 2) on Cases 6, 7, 8, 9, and 10 were normal apart from high serum IgM levels and defective neutrophil mobility in Cases 6, 8, 9, and 10, all of whom had had splenomegaly and frequent infections. The serum IgM of the patients with raised levels was heterogeneous in immunoelectrophoresis and included both kappa and lambda light chains.

The neutrophil mobility of Cases $6,8,9$, and 10 was repeatedly lower that that of the controls and was lower than the mean mobility of $110 \pm 15 \mu \mathrm{m}$ for healthy donors' neutrophils previously established in our laboratory (Table 3). Increased mobility of the neutrophils of Cases 8, 9, and 10 was seen in the presence of $10^{-3} \mathrm{~mol} / \mathrm{l}$ levamisole and $5-10 \mathrm{mmol} / 1$ ascorbic acid.
Table 1 Tests of specific immunity*

\begin{tabular}{|c|c|c|c|c|c|}
\hline & \multicolumn{5}{|l|}{ Case } \\
\hline & 6 & 7 & 8 & 9 & 10 \\
\hline \multicolumn{6}{|c|}{ Immunoglobulins† (IU/ml) } \\
\hline IgG & 152 & 129 & 270 & 130 & 100 \\
\hline $\operatorname{IgA}$ & 266 & 242 & 70 & 29 & 15 \\
\hline IgM & $420^{*}$ & 74 & $500^{*}$ & $524 *$ & $400^{*}$ \\
\hline IgE & 2 & ND & 9 & 2 & 6 \\
\hline ASO titre & 64 & ND & 64 & 64 & 8 \\
\hline \multicolumn{6}{|l|}{ Blood lymphocytes } \\
\hline $\begin{array}{l}\text { PHA response } \ddagger \\
\text { T- and B-cells } \S\end{array}$ & $\begin{array}{l}4 \cdot 7-80 \\
\text { Normal }\end{array}$ & \multicolumn{4}{|c|}{$\begin{array}{lll}4 \cdot 6-160 & 4 \cdot 6-100 & 2 \cdot 5-69 \\
\text { Normal Normal Normal }\end{array}$} \\
\hline
\end{tabular}

* Results are normal for age unless indicated by asterisk. $†$ Measured by radial immunodiffusion. $\ddagger$ Results as unstimulated and peak stimulated values for tritiated thymidine uptake; disintegrations/min $\times 10^{-3}$ per $10 \mu \mathrm{l}$ whole blood, with phytohaemagglutinin stimulation. §Blood lymphocyte populations, T-cells as E-rosette forming cells and B-cells by surface immunofluorescence. $\mathrm{ND}=$ not done.

Table 2 Tests of nonspecific immunity

\begin{tabular}{|c|c|c|c|c|c|}
\hline & \multicolumn{5}{|l|}{ Case } \\
\hline & 6 & 7 & 8 & 9 & 10 \\
\hline \multicolumn{6}{|l|}{ Complement } \\
\hline Total haemolytic * & 100 & & 100 & 100 & 100 \\
\hline C3t & 88 & & 128 & 108 & 92 \\
\hline $\begin{array}{l}\text { Yeast opsonisation } \neq \\
\text { Polymorphs }\end{array}$ & 3 & 3 & 4 & 3 & 4 \\
\hline $\begin{array}{l}\text { Number }\left(\times 10^{-9}\right) \\
\text { NBT } \S\end{array}$ & $2-4$ & & $\begin{array}{r}3-5 \cdot 4 \\
28-100\end{array}$ & $\begin{array}{l}2 \cdot 3-3 \cdot 3 \\
10-62\end{array}$ & \\
\hline Bacterial kill甲 & 0.08 & & 0.08 & & \\
\hline
\end{tabular}

* Kinetic method, as percentage of control; normal $>75 . \dagger \mathrm{C} 3$ measured by radial immunodiffusion, normal range $80-180 \mathrm{mg} / 100 \mathrm{ml}$. $¥$ Method of Soothill and Harvey, ${ }^{13}$ normal $>2 \cdot 5$. §Unstimulated and stimulated percent nitroblue tetrazolium reducing cells, method of Park et al.,14 normal stimulated $>50 \%$ \Killing of Staphlyococcus aureus by patients' neutrophils. Result is ratio of colony counts at 140/20 minutes; normal $<0 \cdot 1$, method of Quie et al.15

Table 3 Results of tests of neutrophil mobility*

\begin{tabular}{|c|c|c|c|c|c|c|c|}
\hline & \multicolumn{7}{|c|}{ Case } \\
\hline & 2 & 5 & 6 & 7 & 8 & 9 & 10 \\
\hline \multirow{5}{*}{$\begin{array}{l}\text { Unstimulated } \\
\text { Stimulated } \\
\text { plus } \\
\text { levamisole } † \\
\text { plus ascorbic } \\
\text { acid } \ddagger\end{array}$} & \multicolumn{7}{|c|}{ Distance $(\mu \mathrm{m})$ of neutrophil migration } \\
\hline & 79 & 107 & $46 \pm 15$ & 47 & $30 \pm 3$ & $46 \pm 9$ & $44 \pm 4$ \\
\hline & 145 & 128 & $92 \pm 12$ & 111 & & $87 \pm 10$ & $65 \pm 5$ \\
\hline & & & & & 105 & 70 & \\
\hline & & & & & 99 & 112 & 86 \\
\hline
\end{tabular}

* Mobility measured as $\mu \mathrm{m}$ migration into a $3 \mu \mathrm{m}$ pore size millipore membrane by leading front method of Zigmund and Hirsch. ${ }^{5}$ Standard errors are shown if the test was repeated at least 3 times. †In presence of $10^{-3} \mathrm{~mol} / 1$ levamisole (Janssen Pharmaceuticals). $¥$ In presence of $10^{-2} \mathrm{~mol} / 1$ ascorbic acid. 


\section{Discussion}

The familial occurrence of recurrent infections leading to bronchiectasis and early death points to immunodeficiency. No causes of secondary immunodeficiency were found and the early onset of symptoms suggests a congenital defect, most probably one that is genetically determined. The abnormal findings of splenomegaly, high levels of serum IgM, and defective neutrophil mobility could each be secondary to infections: this is the most likely cause for the splenomegaly since, in Cases 9 and 10, it appeared only after the onset of infections. The cause of the high serum IgM is less clear. There was no evidence of a monoclonal excess ${ }^{3}$ nor was there evidence of disturbed kappa lambda light chain ratios $^{4}$ such as can occur in patients with varied immunodeficiency syndromes, and our patients made isohaemagglutinins normally. Three of the patients with high IgM levels had detectable anti-streptolysin antibodies (an IgG antibody) and tests for cellmediated immunity, including Candida sp. skin test and blood lymphocyte response to phytohaemagglutinin, were normal in all four. Their specific immunity therefore appears to be normal, so we consider that the most likely explanation for the high IgM is recurrent infection. We cannot however completely exclude the possibility that high serum IgM has a more fundamental relationship to the pathogenesis of the immunodeficiency.

The patients' blood neutrophil count was normal, although leucocytosis during infections was slight. Bacterial killing by neutrophils was normal and the only defect was that of mobility. We have, in accordance with current recommendations, avoided the term 'chemotaxis defect' since the commonly used leading front method for measuring neutrophil mobility ${ }^{5}$ does not always distinguish chemokinesis from chemotaxis. ${ }^{6}$ In vitro, the mobility of neutrophils from Cases 8,9 , and 10 was improved in the presence of ascorbic acid and that of Case 8 was also improved by levamisole. Studies in other patients with neutrophil mobility defects ${ }^{7-9}$ suggest that ascorbic acid and levamisole act by way of an alteration of the ratios of cyclic-AMP to cyclic-GMP which in turn influence microtubule assembly. ${ }^{10}$ The drug effect therefore is consistent with a possible underlying biochemical abnormality but it gives little indication of its nature. Neither levamisole nor ascorbic acid treatment was of therapeutic benefit in Case 8, although the lack of response may have been due to pre-existing lung damage. Both the clinical features and laboratory results in Cases 6, 8, 9, and 10 are consistent with a primary defect of neutrophil mobility. The similar symptoms in Cases 3 and 4 suggest that they had the same disease. The case for dominant inheritance in this family is strong and we are not aware of previous reports of dominantlyinherited defects of neutrophil mobility.

Waardenberg's syndrome has a dominant inheritance $^{11}$ though the penetrance is variable. Phenotypic features found in this family include white forelocks, premature greying, perceptive deafness and, in Case 10 , ptosis and eye abnormalities. The occurrence of a neutrophil mobility defect in our family with Waardenberg's syndrome may result from a single metabolic defect or it may be a coincidence. The case for a common mechanism could derive support from the neutrophil mobility and bacterial killing defects which occur in another disorder of pigmentation: Chediak Higashi syndrome. ${ }^{7} 8$ Not enough patients with Waardenberg's syndrome have been studied to exclude this hypothesis, but Waardenberg's syndrome is not rare and we know of only one other patient in whom infections were a problem. ${ }^{12}$ That patient had a ventriculo-septal defect and died with pneumonia. In other reviews and case reports of Waardenberg's syndrome excess infections are not reported, and there was no clear evidence for excess infections in Case 1 in our family, so the possibility that this finding was coincidental remains.

We thank $\operatorname{Dr} E \mathrm{H}$ Back, Dr A P Norman, Dr R Dinwiddie, and Professor J F Soothill for allowing us to study their patients, Professor J F Soothill for constructive criticism of the manuscript, and Mrs J A Dicker for secretarial assistance.

\section{References}

1 Snyderman R, Pike M C. Disorders of leukocyte chemotaxis. Pediatr Clin N Am 1977; 24 : 377-93.

2 Farhoudi A, Harvey B M, Soothill J F. Clinicopathological findings in patients with primary and secondary defects of neutrophil mobility. Arch Dis Child 1978; 53: 625-30.

3 Danon F, Seligmann M. Serum monoclonal immunoglobulins in childhood. Arch Dis Child 1973; 48: 207-11.

4 Barandun S, Morell A, Skvaril F, Oberdorfer A. Deficiency of k- or $\lambda$-type immunoglobulins. Blood 1976; 47: 79-89.

5 Zigmund S H, Hirsch J G. Leukocyte locomotion and chemotaxis. New methods for evaluation and demonstration of a cell-derived chemotactic factor. J Exp Med 1973; 137: 387-410.

- Keller H U, Wilkinson P C, Abercrombie M. A proposal for the definition of terms related to locomotion of leucocytes and other cells. Clin Exp Immunol 1977; 27: 377-80.

7 Boxer L A, Watanabe A M, Rister M, Besch H R, Jr, Allen J, Baehner R L. Correction of leukocyte function in Chediak-Higashi syndrome by ascorbate. $N$ Engl J Med 1976; 295: 1041-6.

8 Boxer L A, Rister M, Allen J M, Baehner R L. Improvement of Chediak-Higashi leukocyte function by cyclic guanosine monophosphate. Blood 1977; 49: 9-17. 
9 Gallin J I, Malech H L, Wright D G, Whisnant J K, Kirkpatrick C H. Recurrent severe infections in a child with abnormal leukocyte function: possible relationship to increased microtubule assembly. Blood 1978; 51 : 919-32.

10 Oliver J M. Cell biology of leukocyte abnormalities: membrane and cytoskeletal function in normal and defective cells. Am J Pathol 1978; 93: 221-59.

11 Pantke O A, Cohen M M. The Waardenberg syndrome. Birth Defects 1971; 7: No 7, 147-52.

12 Parekh P, Singh S D, Dulhani J D, Jain N M. Waardenberg's syndrome. Indian Pediatr 1976; 13 : 465-8.

13 Soothill J F, Harvey B M. Defective opsonisation, a common immunity deficiency. Arch Dis Child 1976; 51: 91-9.
14 Park B H, Fikrig S M, Smithwick E M. Infection and nitroblue tetrazolium reduction by neutrophils: a diagnostic aid. Lancet 1968; ii: 532-4.

15 Quie P G, White J G, Holmes B, Good R A. In vitro bactericidal activity of human polymorphonuclear leukocytes: diminished activity in chronic granulomatous disease of childhood. J Clin Invest 1967; 46: 668-79.

Correspondence to Dr A R Hayward,University of Colorado Medical Center, Department of Pediatrics, 4200 East Ninth Avenue, Denver, Colorado 80262, USA.

Received 15 January 1980

The following articles will appear in future issues of this journal:

Factors causing rickets in institutionalised handicapped children on anticonvulsant therapy $Y$ Morijiri and T Sato

Cytotoxicity of lymphocytes in the newborn $M$ Xanthou, E Mandyla-Sfagou, C Economou-Mavrou, and $N$ Matsaniotis

A polymorph bactericidal defect and a lupus-like syndrome $R J$ Levinsky, $B$ A $M$ Harvey, $D M$ Roberton, and $O H$ Wolff

Transient tachypnoea of the newborn: two distinct clinical entities? H L Halliday, G McClure, M M Reid

Inappropriate secretion of antidiuretic hormone in infants with respiratory infections $R \boldsymbol{P} A$ Rivers, $M L$ Forsling, and $R P$ Olver

Croup, recurrent croup, allergy, and airways hyper-reactivity $M$ Zach, A Erben, and A Olinsky 